\title{
Hedging Effectiveness of Commodities in the Stock Portfolio: Empirical Evidence from Pakistan Stock Exchange using Multivariate GARCH Models
}

\author{
Waqas Hanif * Muhammad $\operatorname{Khan}^{\dagger}$
}

\begin{abstract}
This study explores the hedging effectiveness of oil and gold assets in Pakistani stock market. We incorporate three multivariate GARCH models for hedging potential of oil and gold assets in stock market of Pakistan. The DCC model is found fitted among others for empirical analysis. The empirical results indicate that the asymmetric effect is positive (negative) providing that negative shocks tend to increase (decrease) volatility in future more than positive shocks of the same magnitude for stock market and oil (gold). During the Global Financial Crisis 2007-2009, the study finds a positive trend in correlations between oil-stock pair suggesting a lack of portfolio diversification benefit of oil when added in stock portfolio. However, a more prominent negative trend in correlations between gold-stock pair shows that gold proves a potential safe haven asset for stocks in Pakistan. The results also reveal that investors must adjust their hedging position in oil and gold assets for their portfolio of stocks across the study period, as the optimal hedge ratios for stock-oil/gold pairs are dynamic in nature. Overall, the average negative values of hedging effectiveness indicate that unhedged portfolio performs better than the hedged ones. These results contain implications for different stakeholders including policymakers, portfolio managers, domestic and international investors.
\end{abstract}

Keywords: Pakistan stock exchange, commodity market, multivariate GARCH models, hedging effectiveness

\section{Introduction}

The Global Financial Crisis 2007-2009 significantly increased the instability and risk in portfolio investment in global financial markets ${ }^{1}$. Under such circumstances, the investors are indifferent regarding their investment and returns on investment. The investors also require minimizing risk through portfolio diversification and higher returns coming from risky assets. The technology crash, 2002, showed an inverse relationship among equities and commodities forcing global investors, portfolio managers, wealthy individual(s) and

\footnotetext{
*Ph.D (Scholar), Department of Management Sciences, Iqra University, Islamabad Campus, Pakistan.

E-mail: waqashanif085@gmail.com

${ }^{\dagger}$ Department of Management Sciences, Iqra University, Islamabad Campus, Pakistan. E-mail: khann.muhammad@gmail.com

${ }^{1}$ According to Business Cycle dates of National Bureau of Economic Research (NBER) Financial crisis start in December 2007 and end in June 2009 (http://www.nber.org/cycles/US_Business_Cycle_Expansions_and_Contractions_20120423.pdf).
} 
institutional investors to hedge their equity position by investing in commodity markets (Erb \& Harvey, 2006; Gorton \& Rouwenhorst, 2006; Greer, 2000). As a result, investors made investment(s) of 13 billion dollars in 2003, and later on, the sum increased over 200 billion dollars in 2008 for commodities (Tang \& Xiong, 2012). Moreover, according to Ebrahim, Inderwildi, and King (2014), fluctuations in commodity prices affect financial sector, consumption, industrial production, inflation, and unemployment of an economy. Therefore, the study of volatility dynamics between financial market and commodities becomes important for the integration between both markets. This can provide new ways to investors concerning the diversification or hedging of risk inherent in portfolio investment.

In commodity markets, oil and gold are the most tradable commodities around the world (Yaya, Tumala, \& Udomboso, 2016). For oil importing countries like Pakistan, the crude oil provides a vital input for production and, at the same time, its prices are largely influenced by demand and supply shocks. In Pakistan, a large quantity of oil is imported from Middle East countries especially Saudi Arabia because; indigenous resources are not enough to satisfy domestic oil requirements. According to the US Energy Information Administration, the crude oil imports increased by 12\% from 2014 to 2015 and oil consumption dramatically increased on average 431,000 barrel per dollar in 2015 for Pakistan. However, increase in international oil prices put pressure on external accounts and imported oil contributes around 30 percent in Pakistan's total imports (Haider, ud Din, \& Ghani, 2012). In broader perspectives, fluctuations in crude oil prices disturb the import bill of an economy. Furthermore, a rise in inflation leads to a rise in the prices of oil, which results in a higher cost of business or cost of production of companies (Arouri \& Nguyen, 2010). A rise in cost of production shift to customers in the form of higher prices, which lead to lower demand (Bernanke, 2006). Lower demand and higher production cost decrease production and lead to higher unemployment in the country (Lardic \& Mignon, 2008). Accordingly, the company's profit(s) decrease and the value of shareholders goes down. On the contrary, gold is considered as the best asset in investment portfolio because gold provide hedging opportunities against inflationary pressures and acts as safe haven due to its lower risk in financial markets (Reboredo, 2013; Shahbaz, Tahir, Ali, \& Rehman, 2014; Emmrich \& McGroarty, 2013; Tuysuz, 2013; Miyazaki, Toyoshima, \& Hamori, 2012). Furthermore, the gold is also assumed to be an inflation proof investment which minimizes the risk during recession periods (Hammoudeh, Malik, \& McAleer, 2011). In light of the available literature, a rise in inflation undermines the value of stock as companies make less profit(s) during the economic turmoil, due to the reason that investors move from the risky stock market by selling shares and buying gold as an alternative (Pettinger, 2011).

Pakistan economy is not directly hit by Global Financial Crisis 2007-2009 because of relatively less global connectivity with the world economy in comparison to its neighbors such as India and China (Draz, 2011), nevertheless, the country is indirectly affected in shape of trade losses (Ali \& Afzal, 2012). Domestic problems made the condition poorer because suitable strategy could not be made for tackling the trade losses (World Bank, 2009). This crisis pressed Pakistan's real gross domestic product from $8 \%$ to $3 \%$ along with an increase of more than $25 \%$ in general price level as well as unemployment (Nanto, 2009). Undoubtedly, Pakistan's economy is hit by this crisis but it was not the primary reason of all its economic issues (Draz, 2011). In additional to its external problems, the country 
was facing internal political and economic challenges (Husain, 2009). Currently, Pakistan's economy is facing long standing structural issue, security related problems, energy sector challenges and difficult investment climate couple with persistent fiscal imbalances widely contributed to hampering economic growth ${ }^{2}$. Among all these challenges, Pakistan Stock Exchange (PSX) has experienced 14,814 points in December 2007 and touched a peak of 15,373 points on April 20, 2008 (Muhammad, Hussain, Ali, \& Jalil, 2009). A major crash was witnessed with 9,144 points on August 27 in the same year (Peiris, 2008) which further declined by 4,929 points in January 2009. Afterwards, growing trends of investments have been observed in KSE-100 index and reached up to 47,807 points till the end of December 2016. Furthermore, in the recent years, a growing trend of investment is observed, causing a many fold increase in the portfolio investments by domestic and international investors. Due to this higher trend in the market, the Morgan Stanley Capital International (MSCI) included the Pakistan Stock Exchange (PSX) in the emerging market index ${ }^{3}$.

The above trends show that a fluctuation in equity market will continue in the near future. During the period of adverse financial markets, investors strive to minimize/avoid large losses. In nutshell, investors require a minimum risk or avoiding down markets through hedging or portfolio diversification by using alternative investment classes which maintain negative or low correlations with stocks in portfolio (Chkili, 2016). Furthermore, portfolio managers need to adopt potential hedge instruments during their investment decisions. However, a limited number of studies have explained the impact of commodities on the stock market in Pakistan. For example, Ansar and Asaghar (2013) found a weak positive association between oil prices, consumer price index and KSE-100 Index. Siddiqui and Muhammad (2013) found a positive linkage between oil and stock prices in Pakistan during a period 2003-2012. Further, Irshad, Bhatti, Qayyum, and Hussain (2014) reported the absence of any long-term relation among oil, gold and the stock market from 2002-2010.

Due to the contradictory nature of the results on relationship between the commodity market and the equities, the present study intends to further explore the hedging effectiveness of oil and gold in stock portfolio. To the best of our knowledge, this study is the first attempt to investigate hedging potential of commodities such as oil and gold in Pakistan Stock Exchange (PSX). In this study, we employed multivariate GARCH model specifications due to the fact that the M-GARCH models are more appropriate compared to the univariate GARCH models (Bauwens, Laurent, \& Rombouts, 2006). For empirical data analysis, we used three multivariate econometrics models, namely, the DCC-GARCH model of Engle (2002), the ADCC model provided by Cappiello, Engle, and Sheppard (2006) and the GO-GARCH model proposed by Van der Weide (2002). The rationale for using several GARCH models is to achieve higher hedging effectiveness as mentioned by Basher and Sadorsky (2016). However, the selection of DCC-GARCH models comes with several advantages. The first advantage is that this method is suitable to study symmetry in the financial time series (Ciner, Gurdgiev, \& Lucey, 2013; Arouri, Jouini, \& Nguyen, 2011; Chang, McAleer, \& Tansuchat, 2011; Sadorsky, 2012, 2014; Lin, Wesseh, \& Appiah, 2014),

\footnotetext{
${ }^{2}$ According to Economic Survey of Pakistan 2016-17 (http://www.finance.gov.pk/survey/chapters_17/04Fiscal.pdf).

${ }^{3}$ According to MSCI annual market classification review, Pakistan will classify from frontier markets to emerging markets (https://www.msci.com/market-classification).
} 
as well as time-varying correlations between financial variables and commodities (Ciner et al., 2013). The DCC model also captures the persistence in correlation and volatility (Basher \& Sadorsky, 2016). Secondly, the ADCC model is extension of the DCC model which allows taking into account the 'asymmetry' in the financial time series (Chkili, 2016). This model also captures the effect of negative and positive news independently (Cappiello et al., 2006; Ederington \& Guan, 2010; Chkili, Hammoudeh, \& Nguyen, 2014; Chkili, 2016). Thirdly, the GO-GARCH model satisfies the requirements like volatility spillover effects under linear transformation, dynamic conditional correlations and variances, persistence in volatility and correlation. Although, this model is more flexible but still difficult to estimate and so is less frequently used in the empirical literature (Basher \& Sadorsky, 2016). For our empirical investigation, several versions of DCC models are estimated. In all cases, a constant auto-regressive term is included in mean equation and adjustments are made on choice of distribution and AR (1) term. For DCC and ADCC models, we employ multivariate t-distribution, whereas, multivariate affine negative inverse Gaussian distribution is for GO-GARCH model. Further, the conditional volatility parameters obtained from these models are used to construct the optimal hedge ratios and hedging effectiveness of oil and gold in stock portfolio (Kroner \& Sultan, 1993). Finally, we compare the hedge ratios obtained from a GARCH process for hedging effectiveness (Chang et al., 2011; Ku, Chen, \& Chen, 2007).

The remaining part of this paper is structured as; a literature review elaborates in Section 2. Section 3 depicts empirical methodology. Section 4 provides data and preliminary findings. Section 5 reports empirical results and discussion. Section 6 presents conclusion.

\section{Review of Literature}

In the literature, the stock markets of both oil importing and exporting economies seem to be influenced by oil shocks. For instance, Filis, Degiannakis, and Floros (2011) analyzed a relation between oil price uncertainty and financial markets in oil importing and exporting economies by applying a dynamic conditional correlation GARCH model. Their results show that stock markets respond positively to increase in oil prices originated by demand side shocks. Arouri and Rault (2012) use the panel cointegration technique and found that oil shocks created a positive impact on stock markets for most of the oil exporting countries. Similarly, Broadstock, Cao, and Zhang (2012) used dynamic conditional correlation model and asset pricing model, concluded oil price risk generate a positive impact on stock returns. Further, they argued stronger correlation over the turbulent time. Cunado and de Gracia (2014) investigated the impact of oil shocks in European markets by incorporating Vector Autoregressive and Vector Error Correction models. The results show that changes in prices in oil market, driven by oil demand shock, respond positively to stock markets for France and Denmark. Abhyankar, Xu, and Wang (2013) scrutinized a association between oil price volatility and stock market in Japan and found a negative impact of changes in oil price on stock market returns for the Japanese. Filis and Chatziantoniou (2014) found similar results for oil-importing countries.

Previously, a large number of studies examined the correlations between equities and 
commodities due to their leading role in an economy. For example, Smith (2002) found a negative correlation between gold and stock returns when examining association between gold and stock prices. A similar result is reported by Büyükşalvarcı (2010) for Turkey. Baur and Lucey (2010) reported a negative linkage between gold and returns in stock market for United States. Baur and Lucey (2010) extended the similar hypothesis for developed and emerging countries and found an inverse relation only in developed stock markets. Hood and Malik (2013) used the GARCH model with the gold price and other commodities and volatility indices. The study concludes that gold is negatively correlated with equities in the stock market. Ibrahim (2012) found that gold returns maintained a negative correlation with stock market returns. Recently, Gürgün and Ünalmış (2014) take a large sample of both developed and developing economies to show a negative relationship between gold and stock markets.

However, oil among energy commodities and gold among metals have a unique position in the financial system due to their high liquidity and frequent tradability (Tiwari \& Sahadudheen, 2015). Further, investors have evaluated the alternative assets for diversification benefits at the time of economic downturns. For example, Arouri, Lahiani, and Nguyen (2015), while analyzing oil investments during the market downturns found that investors prefer the gold investment in these times. Lucey and Tully (2003) examined the mean- variance skewness approach and found that gold provided the diversifying opportunity in optimal portfolio. Further, Conover, Jensen, Johnson, and Mercer (2009) tested the efficiency of gold as best diversified asset in portfolio and found that gold provides the best diversification opportunity in a portfolio of stock and gold commodity but not for the other commodities i.e. platinum and silver. Baur and Lucey (2010) tested the hedging and safe haven potentials of gold and found that gold had not maintained a safe haven asset for bonds but retained a similar property only for stocks during bad times in the stock market. Bredin, Conlon, and Potì (2015) incorporated the Wavelet approach and concluded that gold has the feature of safe haven for one year (and not only fifteen days) during the turbulent time in the financial market. Pukthuanthong and Roll (2011) documented the relationship between gold price and exchange rate and found that gold price is positively linked with the devaluation of local currency. Joy (2011) investigated the gold property as a safe haven or hedge against United States currency to conclude that gold would not maintain a status of safe haven during stress periods in market because gold and dollar move in the same direction during market disruption. Some other studies also explored a hedging potential of gold for inflation in different countries. For example, Le Long, De Ceuster, Annaert, and Amonhaemanon (2013) investigated the gold characteristic as hedge against inflation for Vietnam and found that gold provides the ability of hedging against inflation. Omag (2012) reports similar results for Turkey. These findings reconfirmed by Shahbaz et al. (2014) for Pakistan and Batten, Ciner, and Lucey (2014) for United States. Recently, Bampinas and Panagiotidis (2015) examined the hedging ability of metal commodities for United States and United Kingdom using a large data set and found that gold maintains its status against increase in the general price level than silver in both economies. For hedging potentials of oil, a few authors found that hedge ratios are time varying. For example, Chang et al. (2011) found a dynamic trend in hedge ratios by incorporating several MGARCH models. Lin et al. (2014) studies the hedge properties 
of oil and concluded that oil should be a part of stocks portfolio for Ghana and Nigeria. Sadorsky (2014) studied the volatility dynamics of oil, wheat and copper in stock markets for emerging countries. The results of the study disclosed that oil provide cheapest hedge on comparison and investors should update hedge ratios regularly.

The above discussion highlights the following deficiencies of the previous literature. First, many existing studies are unable to capture the time-varying correlations among oil, gold and stock for the Pakistan economy. Second, the previous studies are also unable to test the hedging effectiveness of oil and gold in traditional portfolio of stocks. Finally, the literature either incorporates simple econometrics techniques without providing a comparison among models or it comes up with competing results using on different GARCH models. A comprehensive approach, based on a range of multivariate models, can be helpful for an in-depth analysis of dynamic hedge ratios and hedging effectiveness (Basher \& Sadorsky, 2016).

\section{Methodology}

This study uses the time-varying multivariate GARCH models such as DCC model presented by Engle (2002), ADCC model provided by Cappiello et al. (2006) and GO-GARCH model proposed by Van der Weide (2002) to construct the time-varying correlations. Further, these correlations are used to build the optimal hedge ratios among gold / KSE-100 Index and oil / KSE-100 Index.

Let, $r_{t}$ is the return of assets with vectornx 1 . The $I_{(t-1)}$ is the information set of AR (1) term for return $r_{t}$ can be written as:

$$
\operatorname{Return}_{t}=\mu+a r_{t-1}+\epsilon_{t}
$$

In equation (1) errors are shown as $\epsilon_{t}=H_{t}^{(1 / 2)} z_{t}$, where $H_{t}$ is covariance matrix of returns at time $\mathrm{t}$ and $z_{t}$ is a vector $n x$ 1of independent and identically distributed of randomly residuals. The DCC model presented by Engle (2002), is estimated in two steps. In first step, the GARCH parameters are estimated and correlations are estimated in second step. Let, $H_{t}$ can be decomposed as follows:

$$
H_{t}=D_{t} R_{t} D_{t}
$$

Where $D_{t}$ is $n x n$ diagonal matrix of dynamic standard deviations on diagonal, estimated from univariate GARCH models and $H_{t}$ is conditional covariance matrix. $R_{t}$ represents a dynamic correlation matrix.

$$
\begin{gathered}
D_{t}=\operatorname{diagonal}\left(h_{1, t}^{1 / 2}, \ldots . . h_{n, t}^{1 / 2}\right) \\
R_{t}=\operatorname{diagonal}\left(q_{1, t}^{-1 / 2}, \ldots . . q_{n, t}^{-1 / 2}\right) Q_{t}=\operatorname{diagonal}\left(q_{1, t}^{-1 / 2}, \ldots \ldots q_{n, t}^{-1 / 2}\right)
\end{gathered}
$$


In equation (3) $h$ notation indicates the time-varying covariance matrix estimated through univariate GARCH models and the elements of $H_{t}$ (conditional covariance matrix) for $\operatorname{GARCH}(1,1)$ model can be written as:

$$
h_{i, t}=\omega_{i}+\alpha_{i} \epsilon_{i, t-1}^{2}+\beta_{i} h_{i, t-1}
$$

The symmetric positive definite matrix $Q_{t}$ in equation (4) is decomposed into the following:

$$
Q_{t}=\left(1-\theta_{1}-\theta_{2}\right) \Phi+\theta_{1} z_{t-1} z_{t-1}^{\prime}+\theta_{2} Q_{t-1}
$$

In equation (6) $Q_{t}$ is $n x n$ is a diagonal correlation matrix of residuals $z_{i}$ at time t. The parameters $\theta_{1}$ and $\theta_{2}$ are used to construct the mean reverting correlations. The sum value of these parameters is less than one indicating the time-varying correlations are not constant over time.

The conditional correlation estimator is:

$$
\rho_{i, j, t}=\frac{q_{i, j, t}}{\sqrt{q_{i, i, t} q_{j, j, t}}}
$$

Subsequently, the DCC model does not address the leverage effect which is also good and bad news impact on volatility in short, the asymmetric effect. However, Cappiello et al. (2006) provided multivariate asymmetric DCC-GARCH (ADCC-GARCH) technique. We simply extend the equation (5) with the asymmetric function, as shown in the following:

$$
h_{i, t}=\omega_{i}+\alpha_{i} \epsilon_{i, t-1}^{2}+\beta_{i} h_{i, t-1}+d_{i} \epsilon_{i, t-1}^{2} I\left(\epsilon_{i, t-1}\right)
$$

The asymmetric $\operatorname{GARCH}(1,1)$ in equation (8), presents the indicator function $I(\epsilon)$ for $\epsilon>0$. In asymmetric dynamic conditional correlation GARCH model. The negative value of $\mathrm{d}$ indicate that positive conditional residuals tend to decrease the volatility in future more than negative shocks of the same magnitude. Further, notations such as $\alpha$ and $\beta$ are for $\mathrm{ARCH}$ and GARCH effects, respectively. The symmetric positive definite matrix $\left(Q_{t}\right)$ for ADCC model are given by:

$$
Q_{t}=\left(\bar{Q}-A^{\prime} \bar{Q} A-B^{\prime} \bar{Q} B-G^{\prime} \bar{Q}^{-} G\right)+A^{\prime} z_{t-1} z_{t-1}^{\prime} A+B^{\prime} Q_{t-1} B+G^{\prime} z_{t}^{-} z_{t}^{\prime} \bar{G}
$$

Where A, B and G are $n x n$ parameter matrices, standardize residuals $\left(z_{t}^{-}\right)=z_{t}$ and $z_{t}<1$ and 0 otherwise. The unconditional matrixes are $\bar{Q}$ and $\overline{Q^{-}}$represent the $z_{t}$ and $z_{t}^{-}$, respectively.

Further, the GO-GARCH model Van der Weide (2002) is based on the assumption that returns of an asset are generated by a set of unobserved underlying factors that heteroskedastic. Consider the asset returns (r) at time $t$ as a function of mean $(m)$ at time $t$, error term $(\epsilon)$ at time $t$ with autoregressive term AR (1) than:

$$
r_{t}=m_{t} \epsilon_{t}
$$


The maps $r_{t}-m_{t}$ a set of unobserved underlying independent factors $(f)$ at time $t$. Hence,

$$
\epsilon_{t}=A f_{t}
$$

A is a mixing matrix which is decomposed into square root of the unconditional covariance $\left(\Sigma^{1 / 2}\right)$ and an orthogonal matrix, $U$, so that: $A=\Sigma^{1 / 2} U$. In mixing matrix rows indicate the assets and columns indicate the factors. The factors in the matrix are shown as:

$$
f_{t}=H_{t}^{1 / 2} z_{t}
$$

In equation (12), random variable $\left(z_{t}\right)$ is having zero mean and one variance. Further, $h_{i, t}$ is conditional variance of factor which modelled as a GARCH type process. The unconditional distribution of the factors $(f)$, satisfy:

$$
E=\left(f_{t}\right)=0, E=\left(f_{t}, f_{t}^{\prime}\right)=1
$$

By combining the three equations (10), (11) and (12), returns can be represented as:

$$
r_{t}=m_{t}+H_{t}^{1 / 2} z_{t}
$$

The $\left(r_{t}-m_{t}\right)$ is the conditional covariance matrix of the returns is expressed as:

$$
\Sigma_{t}=A H_{t} A^{\prime}
$$

\section{Time-varying Hedge Ratios}

The investors minimize the risk of their portfolios by considering the expected returns. So, the returns of the portfolio of stocks and oil/gold is written as:

$$
R_{H, T}=R_{S, T}-\gamma_{t} R_{o / g t}
$$

Where $R_{H, t}$ is the return of hedge portfolio at time $t$. $R_{S, t}$ and $R_{o / g, t}$ indicate the return of stock, oil/ gold returns at time $t$, respectively. Whereas, $\gamma_{t}$ represents the hedge ratio (HR), which indicates that, the hedger can take the long position (selling position) in dollar in stock by short position (buying position) in dollar in the commodity market. Further, the variance of the hedged portfolio conditional on the information set at the time $(\mathrm{t}-1)$ is written as:

$$
\operatorname{Var}\left(R_{h, t} I_{t-1}\right)=\operatorname{Var}\left(R_{s, t} I_{t-1}\right)-2 \gamma_{t} \operatorname{Cov}\left(R_{o i l / g o l d, t}, R_{s, t} I_{t-1}\right)+\gamma_{t}^{2} \operatorname{Var}\left(R_{o i l / g o l d, t} I_{t-1}\right)
$$

Here, $\gamma_{t}$ indicates the optimal hedge ratios. This expression is equal to zero (Baillie \& Myers, 1991). The information set $I_{t-1}$ of hedge ratio is obtained by taking the partial derivative of variance, written as:

$$
\gamma_{t}^{*} I_{t-1}=\frac{\operatorname{cov}\left(R_{s, t} R_{\text {oil } / \text { gold }, t} \mid I_{t-1}\right)}{\operatorname{Var}\left(R_{\text {oil } / \text { gold }, t} \mid I_{t-1}\right)}
$$


The conditional volatility, obtained from GARCH-process, is used to construct the optimal hedge ratio (Kroner \& Sultan, 1993). Therefore, the following formula is used by taking long position in stocks and short position in oil/gold market.

$$
\gamma_{t}^{*} I_{t-1}=h_{s, o / g, t} / h_{o / g, t}
$$

In equation (19), $h_{s, o / g, t}$ is used for the conditional covariance of returns between stocks and oil/gold assets at time $t$. The $h_{o / g, t}$ notation represents the conditional variance of oil/gold returns at time t. Finally, we use hedging effectiveness index to evaluate the hedging effectiveness of oil/ gold assets, obtained as:

$$
H E=\text { Variance }_{\text {unhedged }}-\text { Variance }_{\text {hedged }} / \text { Variance }_{\text {unhedged }}
$$

\section{Data and Preliminary Findings}

This paper uses the daily closing spot prices on Pakistan stock exchange (KSE-100 Index), gold and crude oil. The KSE-100 index is considered as a benchmark for trading activities (Ali \& Afzal, 2012) in Pakistan Stock Exchange (PSX).

Figure 1a,b,c

Time series plots for KSE-100 Index, Oil and Gold prices
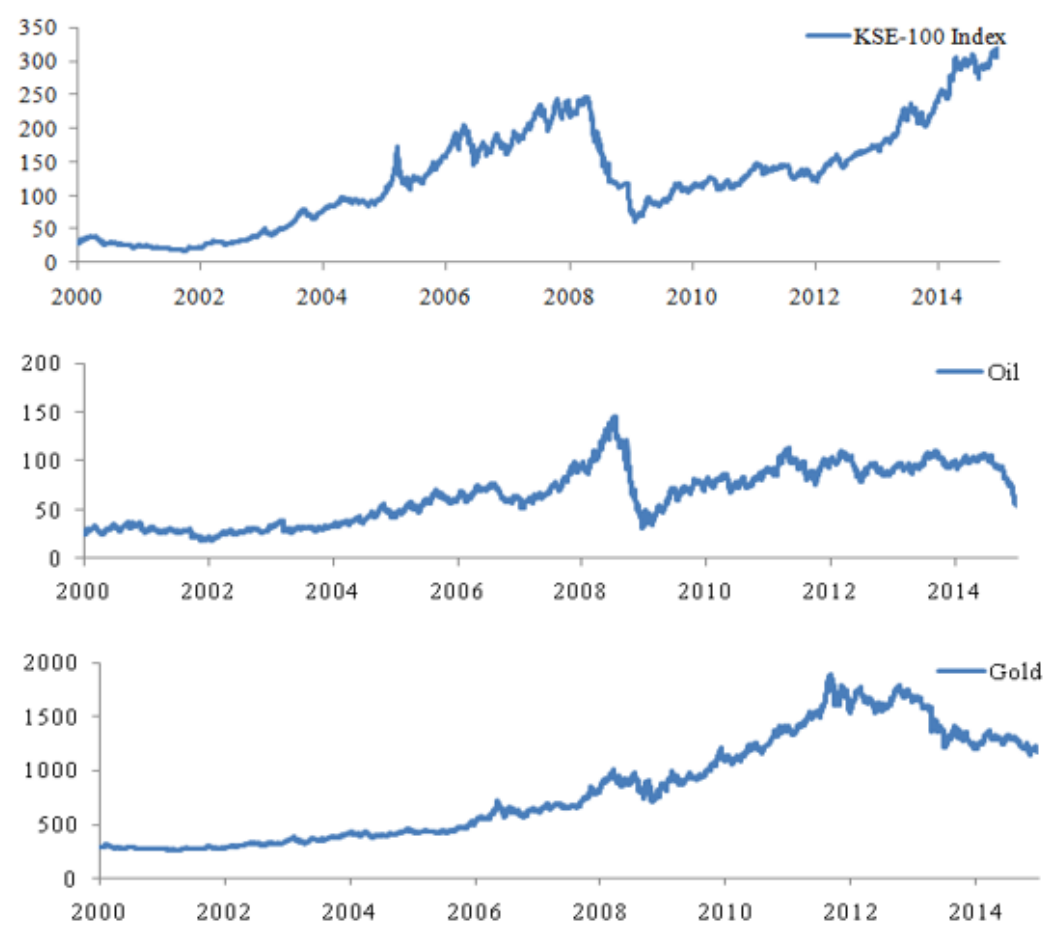
The KSE-100 index prices are converted into US dollar by multiplying the corresponding daily exchange rate (United State Dollar / Pakistan Rupee) in order to make the prices compatible. For study period from January 01, 2000 to December 31, 2014, all the prices are taken from Thomson Router (DataStream). We choose a study time frame for analysis from 2000 because of an increase in trading activities at commodity market after the technology market collapse in this year. The daily returns for all series calculated by Daily Returns $(i, t)=\ln (P i, t / P i, t-1)$ where, $P i, \operatorname{tand} P i, t-1$ are daily closing price $i$ for time $t$ and $t-1$, respectively.

Figures 1, a, b, c show the time trend of the raw data for KSE-100 Index, gold and oil prices. The upward trend in KSE-100 index is noticed from the start of the study period in 2008. But a sudden decrease in the index is observed in the second quarter of 2008 to January 26, 2009 (up to value 60.90 dollar).

Figure 2a,b,c

Time series plots for squared returns, KSE-100 Index, Oil and Gold
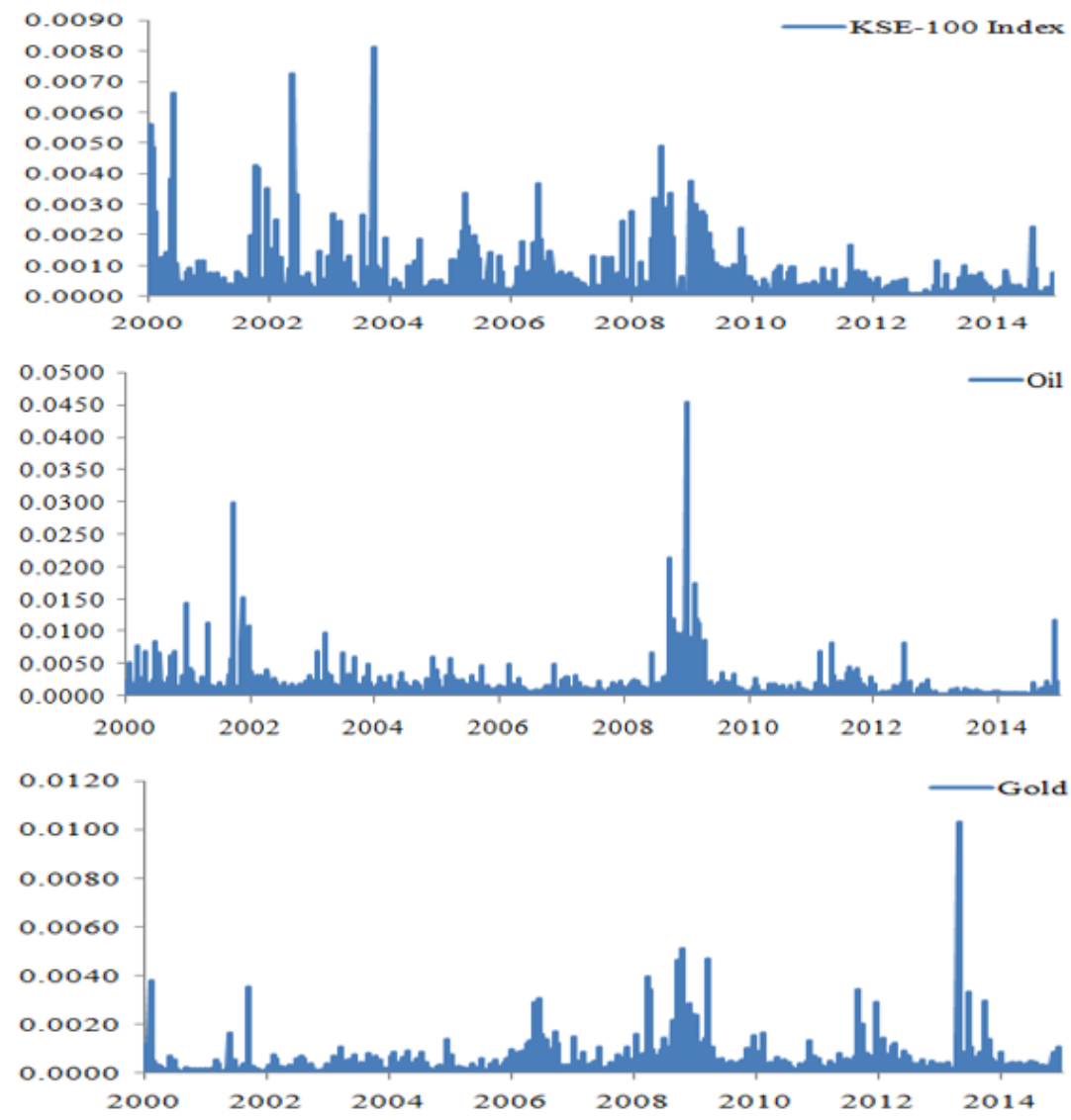
Whereas, the continuing upward trend in oil prices has noticed since 2000 and peaking 145.28 dollars per barrel in July 2008, following a reduction in the short price during the second half of 2008. Finally, an upward trend in oil prices is restored in 2009. The gold prices show a strong upward trend, but some downward trend has also been observed in gold prices at the start of third quarter till the end of 2014. The general view of financial experts holds that gold plays a significant contribution as a hedge instrument as well as an alternative investment instrument in financial markets during turmoil time. Further, figures $2 \mathrm{a}, \mathrm{b}, \mathrm{c}$ illustrates how volatility in all series has changed throughout the study period. For this, the squared daily returns are used as a proxy for volatility. All series show the existence of volatility clustering, which is more prominent during Global Financial Crisis 2007-2009. A few big spikes are also noticed in all series in the other times.

This study reports the descriptive statistics for daily returns for all series in Table 1. KSE-100 Index provides an average return $3.97 \%$ on a daily basis. Oil and gold provide daily average returns of $1.87 \%$ and $3.57 \%$, respectively. This means that gold provides higher returns in comparison to the other commodities (Daskalaki \& Skiadopoulos, 2011; Jensen, Johnson, \& Mercer, 2000). The standard deviation of KSE-100 index is 1.58 and oil show highest standard deviation of 2.36. On the other hand, Gold provides the least standard deviation as 1.14. The coefficient of variation indicates that oil has a large variability which amounts to 126.15 while gold has the least amount of variability comprising 31.86. In addition, the KSE-100 Index provides the amount of variation as 39.70. However, the returns of KSE-100 Index, gold and oil are not normally distributed through Jarque Bera test that rejects the null hypothesis. There is strong proof of ARCH effects in all series as indicated by ARCH (12) LM statistics. Thus, the selection of GARCH models is suitable to analyze the volatility dynamics and hedging effectiveness of stock commodities.

Table 1

\begin{tabular}{|c|c|c|c|}
\hline & KSE-100 Index & Oil & Gold \\
\hline No. of Observations & 3913 & 3913 & 3913 \\
\hline Minimum & -10.1279 & -17.2169 & -10.1624 \\
\hline Maximum & 11.2077 & 21.2765 & 6.8653 \\
\hline Median & 0.0648 & 0 & 0.018 \\
\hline Mean & 0.0397 & 0.0187 & 0.0359 \\
\hline SE. Mean & 0.0252 & 0.0378 & 0.0183 \\
\hline Var & 2.4889 & 5.5807 & 1.3092 \\
\hline Std.Dev & 1.5776 & 2.3623 & 1.1442 \\
\hline Coef.Var & 39.6978 & 126.1473 & 31.8601 \\
\hline Jarque Bera & 2946 *** & $5382^{* * *}$ & $5688^{* * * *}$ \\
\hline $\mathrm{ARCH}(12)$ & $450^{* * *}$ & $498^{* * *}$ & $224^{* * *}$ \\
\hline \multicolumn{4}{|c|}{$\begin{array}{l}\text { SE mean indicates an average of standard error, Var stands for } \\
\text { variance, Std.Dev indicates Standard deviation, Coef. Var } \\
\text { represents the coefficient of variation and J-B indicates Jarque- } \\
\text { Bera test statistics. ARCH (12) is the Lagrange multiplier test } \\
\text { for autoregressive conditional heteroskedasticity of order } 12 \text {. } \\
* * * \text { indicates the rejection of the null hypothesis of normality } \\
\text { and no heteroskedasticity at the } 1 \% \text { level of significance. }\end{array}$} \\
\hline
\end{tabular}

Table 2 indicates unconditional correlations among KSE-100 Index, oil and gold returns. The Pearson correlation between KSE-100 Index and both commodities is insignificant and positive. The highest correlation (i.e. 19.45\%) exists between oil and gold, but positively 
significant at $1 \%$ level, whereas, KSE-100 index and gold exhibit the lowest positive correlations (i.e, $0.32 \%$ ). The correlation between KSE-100 index and oil is as low as $0.59 \%$. The lowest correlations indicate that the stock market in Pakistan is not perfectly correlated with global factors. Our results suggest that diversification benefits can be achieved by adding small amount of investment to oil and gold market. These results are in line with the findings of Chkili et al. (2014) for United States. Further, we investigate this issue in a more careful way in optimal hedge ratio section as the unconditional correlations may not be appropriate for decision making in business because unconditional correlations are unable to account the market conditions.

Table 2

Daily Returns Correlations

\begin{tabular}{|c|c|c|c|}
\hline & KSE-100 Index & Oil & Gold \\
\hline KSE-100 Index & 1 & & \\
\hline Oil & $\begin{array}{c}0.0059 \\
{[0.7142]}\end{array}$ & 1 & \\
\hline Gold & $\begin{array}{c}0.0032 \\
{[0.8407]}\end{array}$ & $\begin{array}{c}0.1945^{* * *} \\
{[0.0000]}\end{array}$ & 1 \\
\hline
\end{tabular}

\section{Empirical Results and Discussion}

\section{The DCC, ADCC and GO-GARCH Models Estimation Results}

The regression results for KSE-100 Index, Oil and Gold estimated through DCC, ADCC and GO-GARCH models are presented in Table 3 and 4 . In mean equation, the estimated coefficients of conditional mean $(\mu)$ estimated through DCC and ADCC models are positive and significant for all markets. The conditional mean values are highest for the stock market index. The estimated coefficients values for a (auto-regressive term) are positive and statistically significant in KSE-100 Index equation, and negatively significant for oil and gold. In variance equation, the volatility persistence i.e., own short term persistence and own long term persistence's coefficients are estimated through ARCH term $(\alpha)$ and GARCH term $(\beta)$, respectively. Our results show common pattern for oil, gold and stock market returns in Pakistan. First, the estimated coefficients values of $\alpha$ and $\beta$ are positive and sum value $(\alpha+\beta>1)$, illustrating that the shocks to volatility do not have the same magnitude in these markets. Second, the small coefficient of ARCH effect indicates that conditional volatility does not change quickly due to the returns innovations. In case of large size of GARCH effect, the conditional volatility series tend to fluctuate gradually over time showing a persistence of shocks. Our results confirm the findings of Arouri et al. (2011, 2015) in United States, Europe and China. These findings suggest that investors and portfolio managers will lose investment in the long run, even if they earn high returns on investment in the short run (see also Rahim and Masih (2016)). Further, the investors and fund managers may implement active investment strategies based on current market shocks and long run persistence in volatility while seeking profit from trading oil, gold markets, and stocks in Pakistan. 
For ADCC model, the estimated coefficients of asymmetric effect $(\gamma)$ are positive for stock market and oil asset, indicating that negative shocks tend to increase the volatility in future more than positive shocks of a similar magnitude. These findings are similar to the prior studies of (Chkili et al., 2014) in four emerging countries, Sadorsky (2014); Basher and Sadorsky (2016) in emerging markets and oil market and Chkili (2016) for BRICS countries. Whereas, the estimated coefficient of asymmetric term is negative for gold indicating that the conditional volatility will decrease in future because of negative residuals. Our findings are consistent with the results of Sadorsky (2014); Basher and Sadorsky (2016); Chkili (2016). The asymmetric feature of stock market's behavior - negative shocks being more important than positive shocks of same magnitude - encourages the investors to go for the hedging opportunities and safe haven assets in order to protect their investments during the bad times.

The shape parameters $(\gamma)$ show the degree of freedom, indicating that as number of degree of freedom reaches to infinity, the shape of t-distribution becomes normal.

Table 3

DCC and ADCC models parameters estimated for stock market, oil and gold assets

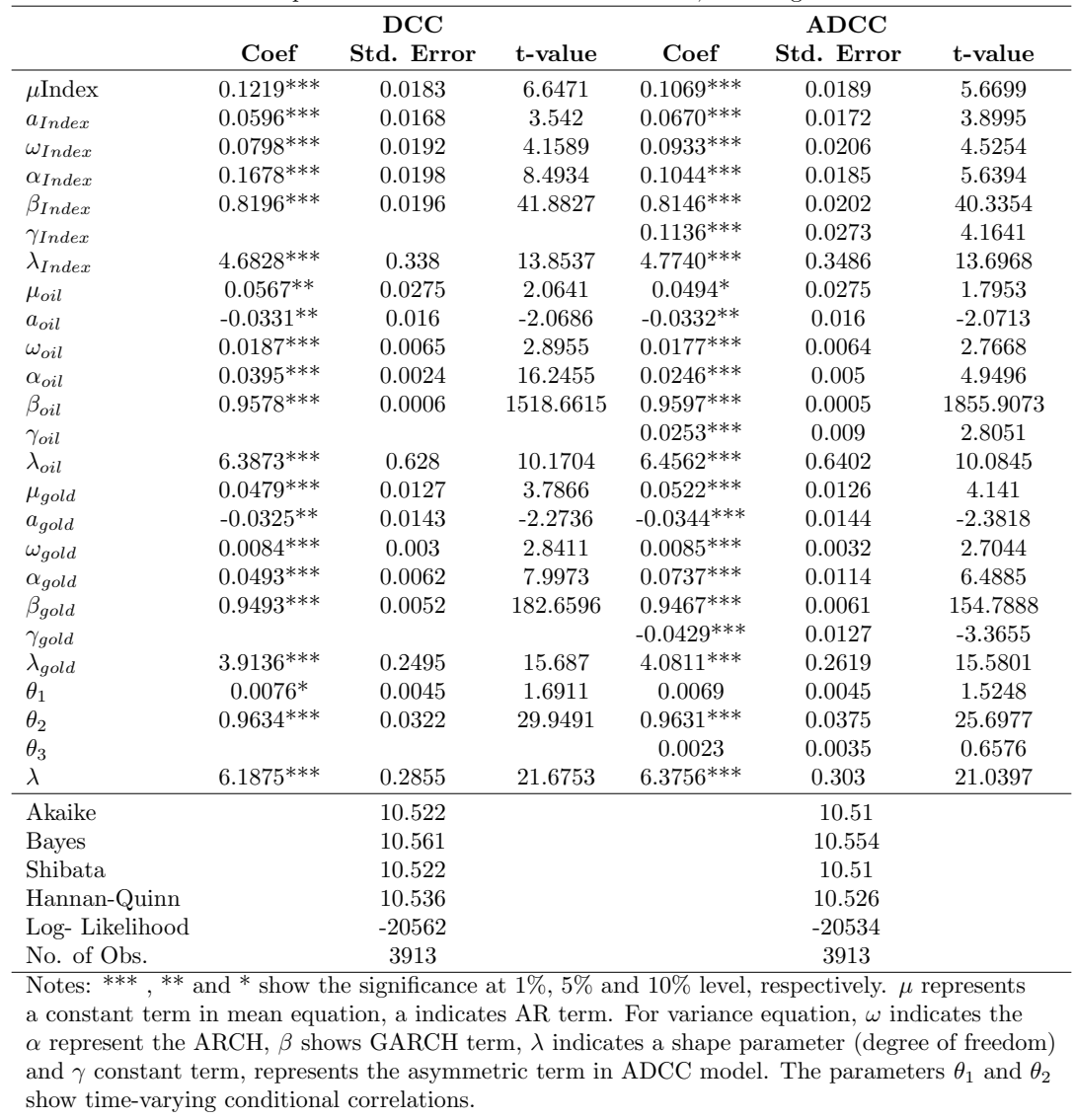


The estimated coefficients of shape parameter provide values such as 4.7 for stock market index. Whereas, oil asset shows highest values (i.e., 6) of estimated coefficients shape parameter. On the other hand, the lowest estimated values (i.e., 4) of shape parameter for gold asset indicates that gold with heavier tails provides better diversification benefit compared with oil asset. These results compliment the findings of Basher and Sadorsky (2016) for their sample of emerging countries. In addition the coefficients for parameter $\theta_{1}$ and $\theta_{2}$ are positive and but only $\theta_{2}$ is insignificant and their sum values are less than one $\left(\theta_{1}+\theta_{2}<1\right)$ indicating the absence of conditional correlations. The results of GOGARCH model (Table 4) for short-term and long-term volatility persistence are in line with the DCC and ADCC models in each of the selected markets.

Table 4

GO-GARCH model parameters estimates

\begin{tabular}{|c|c|c|c|}
\hline \multicolumn{4}{|c|}{ Rotation matrix $U$} \\
\hline & $\mathrm{U}(1)$ & $\mathrm{U}(2)$ & $\mathrm{U}(3)$ \\
\hline $\mathrm{U}(1)$ & -0.0012 & -0.97308 & -0.23047 \\
\hline $\mathrm{U}(2)$ & 0.99997 & -0.00284 & 0.00681 \\
\hline $\mathrm{U}(3)$ & -0.00728 & -0.23045 & 0.97306 \\
\hline \multicolumn{4}{|c|}{ The mixing matrix $\mathrm{A}$} \\
\hline & $\mathrm{A}(1)$ & A (2) & A (3) \\
\hline A (1) & 1.57176 & 0.0147 & 0.0103 \\
\hline A (2) & -0.00924 & 2.3248 & 0.4111 \\
\hline $\mathrm{A}(3)$ & -0.0024 & 0.0261 & 1.1436 \\
\hline \multicolumn{4}{|c|}{ GO-GARCH Model estimation results } \\
\hline & F_1 & F_2 & F_3 \\
\hline$\omega$ & 0.03318 & 0.003837 & 0.006689 \\
\hline$\alpha$ & 0.15065 & 0.042112 & 0.046886 \\
\hline$\beta$ & 0.82693 & 0.954539 & 0.948207 \\
\hline Skew & -0.10175 & 0.106346 & -0.056386 \\
\hline$\lambda$ & 1.14022 & 1.891603 & 0.81953 \\
\hline Log- Likelihood & -20447.62 & & \\
\hline No. of Observations & 3913 & & \\
\hline \multicolumn{4}{|c|}{$\begin{array}{l}\text { Notes: } F_{1}, F_{2} \text { and } F_{3} \text { indicate the set of unobserved under- } \\
\text { lying factors for stock market, oil and, gold assets. It is } \\
\text { usual to present the rotation matrix, mixing matrices and } \\
\text { parameter estimates. U shows the rotation matrix, A } \\
\text { represent the mixing matrix. The rotation matrix is } \\
\text { orthogonal due to UTU=I No standard errors estimated } \\
\text { because of GO-GARCH factors estimates. } \omega \text { indicates the } \\
\text { constant term, } \alpha \text { represents the ARCH, } \beta \text { shows GARCH } \\
\text { term, } \lambda \text { indicates a shape parameter (degree of freedom). }\end{array}$} \\
\hline
\end{tabular}

\section{Dynamic Conditional Correlations}

Figures 3a,b show dynamic conditional correlations of oil-stock and gold-stock pairs using DCC, ADCC and GO-GARCH specifications. The DCC (Black line) and ADCC models (green dots) show a similar pattern in correlations among oil-stock pairs and gold-stock pairs. While, conditional correlations produced from GO-GARCH model (Blue line) significantly differ in comparison to DCC and ADCC models during the crisis and non-crisis periods. During the Global Financial Crisis 2007-2009, prominent positive trend in correlations for oil-stock pair suggest that, oil provides a lack of diversification benefit when oil is added in stock portfolio. However, a considerable negative trend in the correlations be- 
tween gold-stock pair in stress time shows that, gold has a feature of potential safe heaven asset for stocks in Pakistan. The results support the recent findings by Baur and Lucey (2010); Baur and McDermott (2010); Arouri et al. (2015), among others.

a) Dynamic Conditional Correlations: KSE-100 Index / Oil

Figure 3a

Time varying correlations KSE-100 Index / oil

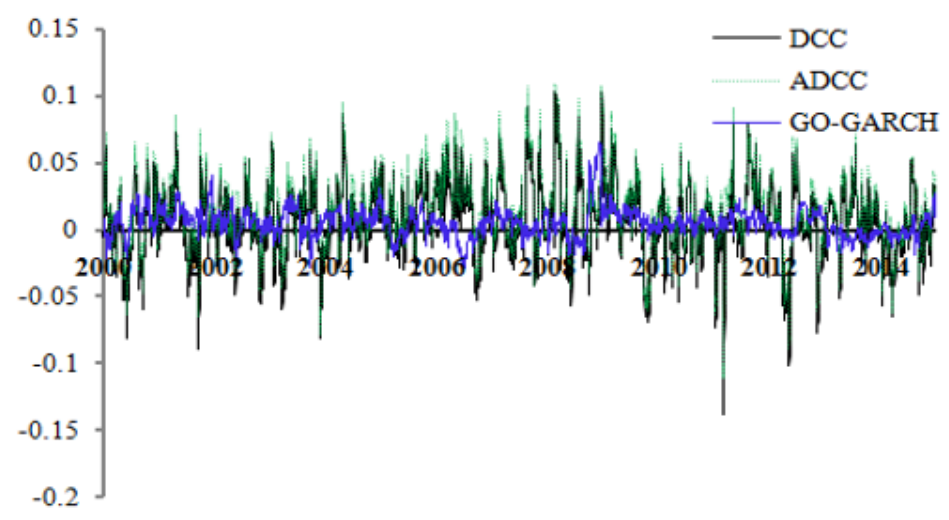

b) Dynamic Conditional Correlations: KSE-100 Index / Gold

Figure $3 b$

Time varying correlations KSE-100 Index / gold

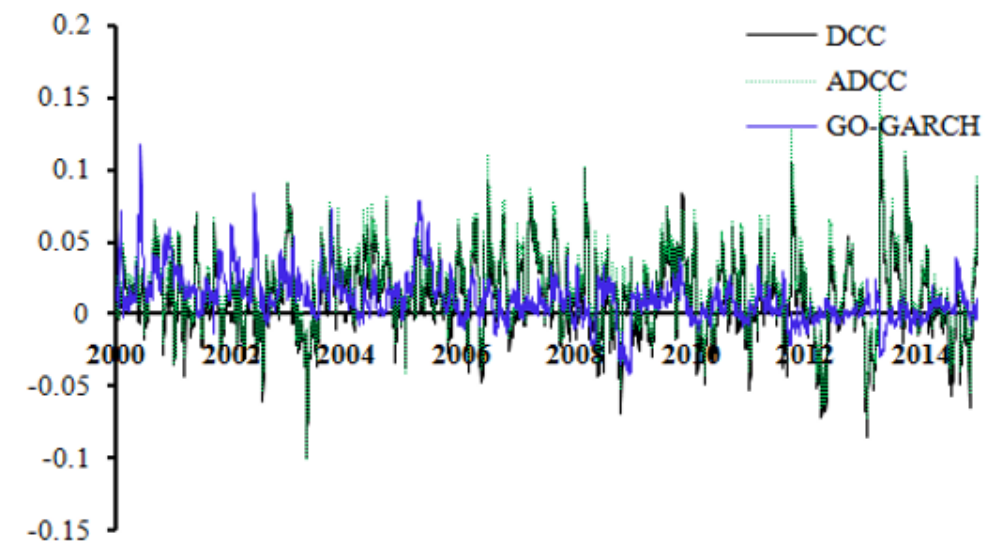

\section{Optimal Hedge Ratios and Hedging Effectiveness}

The table 5 presents optimal hedge ratios between oil-stock and gold-stock pairs as computed through DCC, ADCC and GO-GARCH specifications. The DCC model show that 
mean value of hedge ratio between stock and oil is 0.3 cents indicating that, in order to minimize the risk, a $\$ 1$ long position in stocks should hedged by 0.3 cents investment in the oil market. The average value of hedge ratio is one and 0.4 cents for oil-stock pair as produced from ADCC and GO-GARCH models, respectively. In comparison to oil asset, the average value of hedge ratios for gold-stock pair is 1.2 cents as computed from DCC model. This shows that dollar one long position in stock market should hedged by 1.2 cents investment in the gold market. The average value of hedge ratios between gold-stock pair is 3.3 cents and 0.5 cents for ADCC and GO-GARCH models. Overall, the mean values of hedge ratios between gold-stock are comparatively higher than oil-stock pair's values indicating that oil provides cheapest hedging option than the gold asset. These results reconfirm the finding of Sadorsky (2014). The results also show that in order to minimize the risk, investors need more gold than oil while investing in stock market, which is constant with the previous study by Chkili (2016) in China. Further, the mean values of hedging effectiveness (HE) are negative, indicating that unhedged portfolio perform better than the hedged ones.

Table 5

Hedge Ratio Summary Statistics (Long/Short)

\begin{tabular}{|c|c|c|c|c|}
\hline & Mean & Minimum & Maximum & HE \\
\hline \multicolumn{5}{|c|}{ KSE-100 Index / Oil } \\
\hline DCC & 0.003187 & -0.1482 & 0.097817 & -0.003156 \\
\hline $\mathrm{ADCC}$ & 0.010445 & -0.12428 & 0.130481 & -0.0036745 \\
\hline GO-GARCH & 0.003746 & -0.02172 & 0.009497 & 0.0003889 \\
\hline \multicolumn{5}{|c|}{ KSE-100 Index / Gold } \\
\hline DCC & 0.018851 & -0.16595 & 0.252895 & -0.001377 \\
\hline $\mathrm{ADCC}$ & 0.033013 & -0.16337 & 0.304626 & -0.0013 \\
\hline GO-GARCH & 0.005086 & -0.09169 & 0.009137 & 0.000004922 \\
\hline $\begin{array}{l}\text { Notes: The oil } \\
\text { asset represent } \\
\text { index, whereas } \\
\text { HE is hedging } \\
\text { multivariate m }\end{array}$ & $\begin{array}{l}\text { the KSE- } \\
\text { effectiven } \\
\text { odels. }\end{array}$ & $\begin{array}{l}00 \text { Index rep } \\
\text { s of oil and }\end{array}$ & $\begin{array}{l}\text { sents investr } \\
\text { ld, estimatec }\end{array}$ & $\begin{array}{l}\text { x; the gold } \\
\text { act price } \\
\text { nt in stock. } \\
\text { hrough all }\end{array}$ \\
\hline
\end{tabular}

\section{Time Varying Hedge Ratios}

The figures 4a,b show a trend in hedge ratios as computed through all considered pairs. The DCC (Black line) and ADCC models (green dots) show a similar pattern in hedge ratios. While, optimal hedge ratios produced from GO-GARCH model (Blue line) significantly differ from DCC and ADCC models. This holds true for both stable and unstable period in financial markets. The result for dynamic trend in hedge ratios for oil/gold-stock pairs provide that investors must adjust their hedging position with the passage of time according to bull and bear market's conditions, which confirm the findings of Kang, McIver, and Yoon (2016). 
a) Optimal Hedge Ratio: KSE-100 Index / Oil

Figure 4a

Time-varying hedge Ratios KSE-100 Index / oil

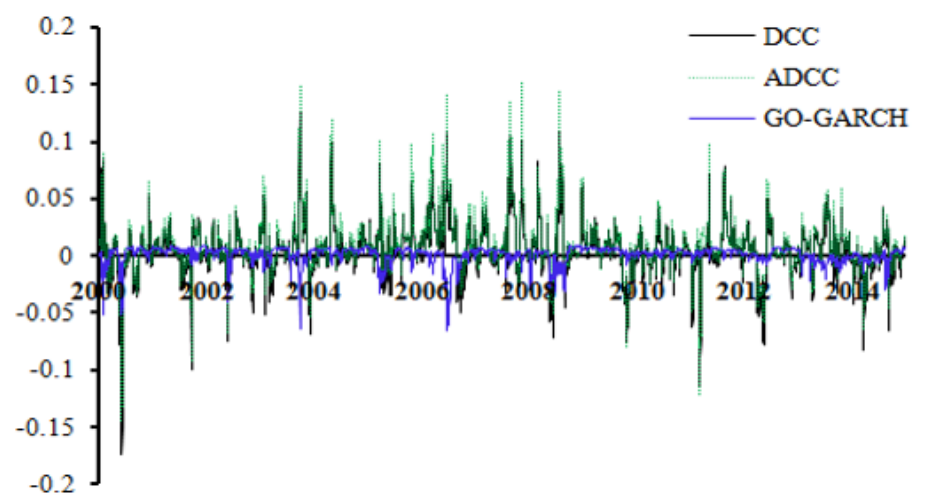

b) Optimal Hedge Ratio: KSE-100 Index / Gold

Figure 4b

Time-varying hedge Ratios KSE-100 Index / gold

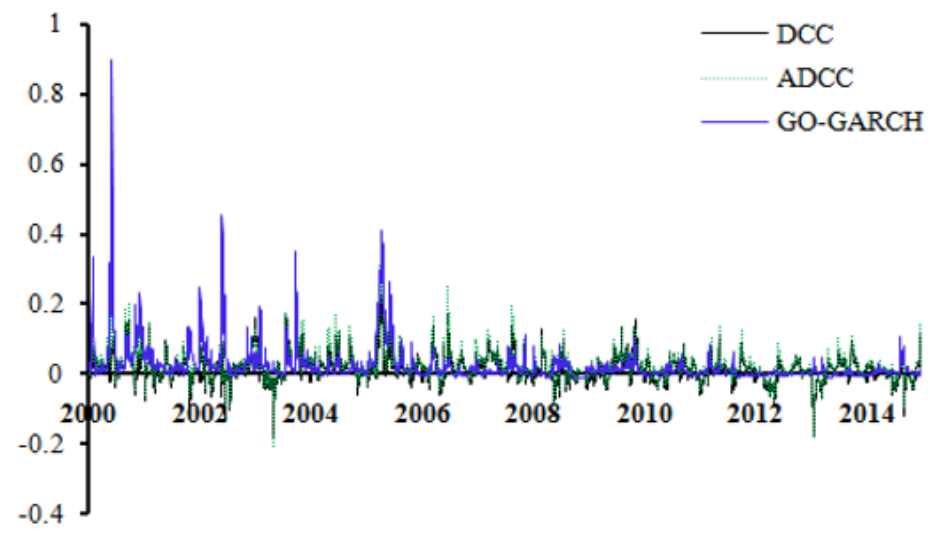

\section{Conclusion}

This paper investigates the hedging effectiveness of commodities in stock portfolio for Pakistan while using the time-varying correlations and volatility dynamics. In doing so, we utilize multivariate GARCH models to estimate the volatility dynamics and dynamic correlations. We find that conditional correlations among oil/gold-stock pairs vary overtime. Our findings suggest that investors choose a safe haven asset such as gold for stocks in Pakistan because a considerable negative trend in correlation between gold-stock pair has been found during the crisis episode 2007-2009. Our study reconfirms the findings of 
(Baur \& Lucey, 2010; Baur \& McDermott, 2010; Arouri et al., 2015) for their selected economies. We further observe that conditional volatilities and returns are not following the integrated generalized autoregressive conditional heteroscedasticity, which shows that risk is involved in these markets. These results suggest that investors, fund managers and market participants implement active investment strategies based on current market shocks and long run persistence in volatility (see also Kumar (2014)).

The empirical results on asymmetric effects provide the evidence that investors and portfolio managers prefer safe haven asset (gold) in order to protect their investments during bad times in market. Turing to the optimal hedging strategies, the evidence shows that investors can reduce the risk without minimizing the returns of their portfolio by adding more gold than oil in their portfolio of stocks. Overall, the negative values of hedging effectiveness (HE) indicate that unhedged portfolio performs better than the hedged portfolio over long time. The findings also suggest that investors must adjust their hedging position over-time while keeping in mind the stock market conditions. On the whole, our study has important implication for market participants that overall risk-adjusted returns performance can be improved by adding commodities to a stock-diversified portfolio.

Further, this study opens several avenues for future research in Pakistan. First, we have examined the hedging potentials of oil and gold assets, future research can be extended by adding more commodities traded in Pakistan Mercantile Exchange (PMEX). Secondly, the study can also be extended to evaluate the effect(s) of oil and gold on bond market and then compare them with the impact of the both commodities on stocks. Additionally, future research can also address the issues regarding hedging strategies and risk diversification through commodities in stocks at sector level because different sectors have different market structures, level of competition and hence are heterogeneous (Narayan \& Sharma, 2011). It may provide comprehensive information to portfolio managers in order to make portfolio allocation decisions at sector level. 


\section{References}

Abhyankar, A., Xu, B., \& Wang, J. (2013). Oil price shocks and the stock market: Evidence from Japan. The Energy Journal, 34(2), 199-222.

Ali, R., \& Afzal, M. (2012). Impact of global financial crisis on stock markets: Evidence from Pakistan and India. Journal of Business Management and Economics, 3(7), $275-282$.

Ansar, I., \& Asaghar, M. (2013). The impact of oil prices on stock exchange and CPI in Pakistan. IOSR Journal of Business and Management (IOSR-JBM). E-ISSN, $32-36$.

Arouri, M. E. H., Jouini, J., \& Nguyen, D. K. (2011). Volatility spillovers between oil prices and stock sector returns: Implications for portfolio management. Journal of International Money and Finance, 30(7), 1387-1405.

Arouri, M. E. H., Lahiani, A., \& Nguyen, D. K. (2015). World gold prices and stock returns in China: Insights for hedging and diversification strategies. Economic Modelling, $44,273-282$.

Arouri, M. E. H., \& Nguyen, D. K. (2010). Oil prices, stock markets and portfolio investment: Evidence from sector analysis in Europe over the last decade. Energy Policy, 38(8), 4528-4539.

Arouri, M. E. H., \& Rault, C. (2012). Oil prices and stock markets in GCC countries: Empirical evidence from panel analysis. International Journal of Finance \& Economics, $17(3), 242-253$.

Baillie, R. T., \& Myers, R. J. (1991). Bivariate GARCH estimation of the optimal commodity futures hedge. Journal of Applied Econometrics, 6 (2), 109-124.

Bampinas, G., \& Panagiotidis, T. (2015). Are gold and silver a hedge against inflation? A two century perspective. International Review of Financial Analysis, 41, 267-276.

Basher, S. A., \& Sadorsky, P. (2016). Hedging emerging market stock prices with oil, gold, VIX, and bonds: A comparison between DCC, ADCC and GO-GARCH. Energy Economics, 54, 235-247.

Batten, J. A., Ciner, C., \& Lucey, B. M. (2014). On the economic determinants of the gold-inflation relation. Resources Policy, 41, 101-108.

Baur, D. G., \& Lucey, B. M. (2010). Is gold a hedge or a safe haven? An analysis of stocks, bonds and gold. Financial Review, 45(2), 217-229.

Baur, D. G., \& McDermott, T. K. (2010). Is gold a safe haven? International evidence. Journal of Banking \& Finance, 34(8), 1886-1898.

Bauwens, L., Laurent, S., \& Rombouts, J. V. (2006). Multivariate GARCH models: A survey. Journal of Applied Econometrics, 21(1), 79-109.

Bernanke, S. B. (2006). The economic outlook. Remarks before the National Italian American Foundation, New York, November 28.

Bredin, D., Conlon, T., \& Potì, V. (2015). Does gold glitter in the long-run? gold as a hedge and safe haven across time and investment horizon. International Review of Financial Analysis, 41, 320-328.

Broadstock, D. C., Cao, H., \& Zhang, D. (2012). Oil shocks and their impact on energy related stocks in China. Energy Economics, 34(6), 1888-1895. 
Büyükşalvarcı, A. (2010). The effects of macroeconomics variables on stock returns: Evidence from Turkey. European Journal of Social Sciences, 14(3), 404-416.

Cappiello, L., Engle, R. F., \& Sheppard, K. (2006). Asymmetric dynamics in the correlations of global equity and bond returns. Journal of Financial Econometrics, 4(4), $537-572$.

Chang, C.-L., McAleer, M., \& Tansuchat, R. (2011). Crude oil hedging strategies using dynamic multivariate GARCH. Energy Economics, 33(5), 912-923.

Chkili, W. (2016). Dynamic correlations and hedging effectiveness between gold and stock markets: Evidence for BRICS countries. Research in International Business and Finance, 38, 22-34.

Chkili, W., Hammoudeh, S., \& Nguyen, D. K. (2014). Volatility forecasting and risk management for commodity markets in the presence of asymmetry and long memory. Energy Economics, 41, 1-18.

Ciner, C., Gurdgiev, C., \& Lucey, B. M. (2013). Hedges and safe havens: An examination of stocks, bonds, gold, oil and exchange rates. International Review of Financial Analysis, 29, 202-211.

Conover, C. M., Jensen, G. R., Johnson, R. R., \& Mercer, J. M. (2009). Can precious metals make your portfolio shine? The Journal of Investing, 18(1), 75-86.

Cunado, J., \& de Gracia, F. P. (2014). Oil price shocks and stock market returns: Evidence for some European countries. Energy Economics, 42, 365-377.

Daskalaki, C., \& Skiadopoulos, G. (2011). Should investors include commodities in their portfolios after all? New evidence. Journal of Banking \& Finance, 35(10), 26062626.

Draz, M. U. (2011). Impact of financial crises on Pakistan and China: A comparative study of six decades. Journal of Global Business and Economics, 3(1), 174-186.

Ebrahim, Z., Inderwildi, O. R., \& King, D. A. (2014). Macroeconomic impacts of oil price volatility: Mitigation and resilience. Frontiers in Energy, 8(1), 9-24.

Ederington, L. H., \& Guan, W. (2010). How asymmetric is US stock market volatility? Journal of Financial Markets, 13(2), 225-248.

Emmrich, O., \& McGroarty, F. J. (2013). Should gold be included in institutional investment portfolios? Applied Financial Economics, 23(19), 1553-1565.

Engle, R. (2002). Dynamic conditional correlation: A simple class of multivariate generalized autoregressive conditional heteroskedasticity models. Journal of Business 83 Economic Statistics, 20(3), 339-350.

Erb, C. B., \& Harvey, C. R. (2006). The strategic and tactical value of commodity futures. Financial Analysts Journal, 62(2), 69-97.

Filis, G., \& Chatziantoniou, I. (2014). Financial and monetary policy responses to oil price shocks: Evidence from oil-importing and oil-exporting countries. Review of Quantitative Finance and Accounting, 42(4), 709-729.

Filis, G., Degiannakis, S., \& Floros, C. (2011). Dynamic correlation between stock market and oil prices: The case of oil-importing and oil-exporting countries. International Review of Financial Analysis, 20(3), 152-164.

Gorton, G., \& Rouwenhorst, K. G. (2006). Facts and fantasies about commodity futures. Financial Analysts Journal, 62(2), 47-68. 
Greer, R. J. (2000). The nature of commodity index returns. The Journal of Alternative Investments, 3(1), 45-52.

Gürgün, G., \& Ünalmış, İ. (2014). Is gold a safe haven against equity market investment in emerging and developing countries? Finance Research Letters, 11 (4), 341-348.

Haider, A., ud Din, M., \& Ghani, E. (2012). Monetary policy, informality and business cycle fluctuations in a developing economy vulnerable to external shocks. The Pakistan Development Review, 609-681.

Hammoudeh, S., Malik, F., \& McAleer, M. (2011). Risk management of precious metals. The Quarterly Review of Economics and Finance, 51(4), 435-441.

Hood, M., \& Malik, F. (2013). Is gold the best hedge and a safe haven under changing stock market volatility? Review of Financial Economics, 22(2), 47-52.

Husain, I. (2009). The role of politics in Pakistan's economy. Journal of International Affairs, 63(1), 1-18.

Ibrahim, M. H. (2012). Financial market risk and gold investment in an emerging market: The case of Malaysia. International Journal of Islamic and Middle Eastern Finance and Management, 5(1), 25-34.

Irshad, H., Bhatti, G. A., Qayyum, A., \& Hussain, H. (2014). Long run relationship among oil, gold and stock prices in Pakistan. Journal of Commerce, 6(4), 6-21.

Jensen, G. R., Johnson, R. R., \& Mercer, J. M. (2000). Efficient use of commodity futures in diversified portfolios. Journal of Futures Markets, 20(5), 489-506.

Joy, M. (2011). Gold and the US dollar: Hedge or haven? Finance Research Letters, 8(3), $120-131$.

Kang, S. H., McIver, R., \& Yoon, S.-M. (2016). Modeling time-varying correlations in volatility between BRICS and commodity markets. Emerging Markets Finance and Trade, 52(7), 1698-1723.

Kroner, K. F., \& Sultan, J. (1993). Time-varying distributions and dynamic hedging with foreign currency futures. Journal of Financial and Quantitative Analysis, 28(4), $535-551$.

Ku, Y.-H. H., Chen, H.-C., \& Chen, K.-h. (2007). On the application of the dynamic conditional correlation model in estimating optimal time-varying hedge ratios. Applied Economics Letters, 14(7), 503-509.

Kumar, D. (2014). Return and volatility transmission between gold and stock sectors: application of portfolio management and hedging effectiveness. IIMB Management Review, 26(1), 5-16.

Lardic, S., \& Mignon, V. (2008). Oil prices and economic activity: An asymmetric cointegration approach. Energy Economics, 30(3), 847-855.

Le Long, H., De Ceuster, M. J., Annaert, J., \& Amonhaemanon, D. (2013). Gold as a hedge against inflation: The Vietnamese case. Procedia Economics and Finance, 5, $502-511$.

Lin, B., Wesseh, P. K., \& Appiah, M. O. (2014). Oil price fluctuation, volatility spillover and the Ghanaian equity market: Implication for portfolio management and hedging effectiveness. Energy Economics, 42, 172-182.

Lucey, B. M., \& Tully, E. (2003). International portfolio formation, skewness and the role of gold. Frontiers in Finance and Economics, 3(1), 49-68. 
Miyazaki, T., Toyoshima, Y., \& Hamori, S. (2012). Exploring the dynamic interdependence between gold and other financial markets. Economics Bulletin, 32(1), 37-50.

Muhammad, S. D., Hussain, A., Ali, A., \& Jalil, M. A. (2009). Impact of macroeconomics variables on stock prices: Empirical evidence in Case of KSE. European Journal of Scientific Research, 38(1), 96-103.

Nanto, D. K. (2009). The global financial crisis: Analysis and policy implications. Diane Publishing.

Narayan, P. K., \& Sharma, S. S. (2011). New evidence on oil price and firm returns. Journal of Banking \& Finance, 35(12), 3253-3262.

Omag, A. (2012). An observation of the relationship between gold prices and selected financial variables in Turkey. Muhasebe ve Finansman Dergisi, 55 .

Peiris, V. (2008). Pakistan facing bankruptcy as world financial crisis deepens. Retrieved November 24, 2010, from World Socialist Web site http://www.wsws.org/articles/2008/oct2008/paki-o20.html.

Pettinger, T. (2011). Factors affecting the price of gold. Retrived from ecomomic help website: http://www.economicshelp.org/blog/3099/economics/factors-affecting-theprice-of-gold.

Pukthuanthong, K., \& Roll, R. (2011). Gold and the Dollar (and the Euro, Pound, and Yen). Journal of Banking \& Finance, 35(8), 2070-2083.

Rahim, A. M., \& Masih, M. (2016). Portfolio diversification benefits of Islamic investors with their major trading partners: Evidence from Malaysia based on MGARCH-DCC and wavelet approaches. Economic Modelling, 54, 425-438.

Reboredo, J. C. (2013). Is gold a hedge or safe haven against oil price movements? Resources Policy, 38(2), 130-137.

Sadorsky, P. (2012). Correlations and volatility spillovers between oil prices and the stock prices of clean energy and technology companies. Energy Economics, 34 (1), 248-255.

Sadorsky, P. (2014). Modeling volatility and correlations between emerging market stock prices and the prices of copper, oil and wheat. Energy Economics, 43, 72-81.

Shahbaz, M., Tahir, M. I., Ali, I., \& Rehman, I. U. (2014). Is gold investment a hedge against inflation in Pakistan? A co-integration and causality analysis in the presence of structural breaks. The North American Journal of Economics and Finance, 28, 190-205.

Siddiqui, M. M., \& Muhammad, N. (2013). Oil price fluctuation and stock market performance-the case of pakistan. Journal of International Business and Economics, 2(1), 47-53.

Smith, G. (2002). London gold prices and stock price indices in Europe and Japan. World Gold Council, 1-30.

Tang, K., \& Xiong, W. (2012). Index investment and the financialization of commodities. Financial Analysts Journal, 68(5), 54-74.

Tiwari, A. K., \& Sahadudheen, I. (2015). Understanding the nexus between oil and gold. Resources Policy, 46, 85-91.

Tuysuz, S. (2013). Conditional correlations between stock index, investment grade yield, high yield and commodities (gold and oil) during stable and crisis periods. International Journal of Economics and Finance, 5(9), 28-44. 
Van der Weide, R. (2002). GO-GARCH: A multivariate generalized orthogonal GARCH model. Journal of Applied Econometrics, 17(5), 549-564.

World Bank. (2009). Impact of Global Financial Crisis on South Asia. Retrieved May 4, 2010, from The World Bank: http://siteresources.worldbank.org /southasiaext/resources/2235461171488994713/34558471232124140958/gfcsouthasiafeb172009.pdf.

Yaya, O. S., Tumala, M. M., \& Udomboso, C. G. (2016). Volatility persistence and returns spillovers between oil and gold prices: Analysis before and after the global financial crisis. Resources Policy, 49, 273-281. 